Basic Health Sciences

Poster

Abstract ID: 22

\title{
Model of a critical size defect in the New Zealand White rabbit's tibia
}

Che Nor Zarida Che Seman ${ }^{\mathrm{a}} \mid$ Zamzuri Zakaria $^{\mathrm{a}} \mid$ Mohamed Azril Mohamed Amin $^{\mathrm{a}} \mid$ Mohd Shukrimi Awang $^{\mathrm{a}}$ | Nazri Mohd Yusof ${ }^{\mathrm{a}}$ | Zunariah Buyong ${ }^{\mathrm{b}}$

${ }^{a}$ Department of Orthopaedics, Traumatology \& Rehabilitation, Kulliyyah of Medicine, International Islamic University Malaysia

${ }^{b}$ Department of Basic Medical Sciences, Kulliyyah of Medicine, International Islamic University Malaysia

Introduction: Critical size defects (CSD) in the long bones of New Zealand White rabbit (Oryctolagus cuniculus) have been used for years as an experimental model for investigation of the effectiveness of a new bone substitute materials. There are varieties of protocols available in the literature. This technical note attempts to present an alternative surgical technique of a CSD in the New Zealand white rabbit tibia. Methods: Thirty-nine New Zealand White rabbits were used in this study. A CSD of approximately 4.5 $\mathrm{mm}$ (width) $\times 9.0 \mathrm{~mm}$ (length) was surgically drilled at the proximal tibial metaphysis, approximately $1 \mathrm{~cm}$ from the knee joint. The surrounding of soft tissue was repositioned and sutured layer by layer with bio absorbable surgical suture. Povidone soaked gauze and bandage were used as a dressing. There is no control group used in this study. Results: This alternative method created good CSD with less bleeding from the muscle observed. No mortality on other surgical complications were observed within 6 weeks, 12 weeks and 24 weeks following surgery. Conclusions: A simple and safe method for performing critical size defect was demonstrated and recommended as an approach for surgery on New Zealand White rabbits.

KEYWORDS: New Zealand White rabbit, critical size defect, surgical approach, bone healing 